\title{
Trends in US Primary Care Provider Patient Advice against Secondhand Smoke Exposure: 2008-2010
}

\author{
Judy Kruger $^{1 *}$, Anna Teplinskaya ${ }^{1}$, Michael C. Fiore ${ }^{2}$ \\ ${ }^{1}$ Office on Smoking and Health, Centers for Disease Control and Prevention, National Center for Chronic Disease Prevention and \\ Health Promotion, Atlanta, USA; ${ }^{2}$ Center for Tobacco Research and Intervention, School of Medicine and Public Health, University \\ of Wisconsin-Madison, USA. \\ Email: ${ }^{*}$ jkruger@cdc.gov
}

Received March $6^{\text {th }}, 2012$; revised April 13 ${ }^{\text {th }}, 2012$; accepted May $25^{\text {th }}, 2012$

\begin{abstract}
Background: Recent studies further expose the dangers of secondhand smoke (SHS) to smokers and nonsmokers alike. The healthcare visit provides a face-to-face opportunity to deliver vital information about those dangers, yet, little is known about whether primary care providers (PCPs) address this topic with their patients in clinical practice. Purpose: We examined primary care providers' advice to patients regarding SHS exposure and the factors associated with such communication. Methods: Data from 3 years $(2008,2009$, and 2010) of physician questionnaires (approximately 1250 family/general practitioners, internists, and obstetricians/gynecologists (OBs/GYNs) were used to examine physician advice to patients with children, to smokers and to nonsmokers to prevent or avoid SHS exposure. Using 2010 data we evaluated descriptive statistics and logistic regression for offering patient advice regarding SHS exposure. Results: Web-based data revealed that almost $90 \%$ of PCPs reported they advise patients with children to keep their children from being exposed to SHS, $80 \%$ advise patients who smoke to avoid exposing others to SHS in their homes and cars, and $70 \%$ advise nonsmokers to avoid general exposure to SHS. Logistic regression analysis indicated that OB/GYNs were less likely to engage in SHS counseling than their family practice/general practitioner colleagues. Conclusions: Physician efforts advising patients to avoid SHS exposure varied little in 2008, 2009, and 2010. Primary care providers, particularly OB/GYNs, are encouraged to advise their patients during routine visits to avoid SHS exposure. More extensive tobacco education and targeted specialty guidelines may be required.
\end{abstract}

Keywords: Smoking Cessation; Physician; Counseling; Secondhand Smoke

\section{Introduction}

Tobacco use in any form jeopardizes health. Americans have been hearing this and other messages about the dangers of tobacco use for more than 50 years. The United States Department of Health and Human Services has documented overwhelming and conclusive biologic, epidemiologic, behavioral, and pharmacologic evidence to support that statement [1]. Information about the health consequences of smoking has continued to grow, with indisputable evidence suggesting more than 1000 people are killed every day in the United States because of the harmful effects of cigarettes, mostly by smoking-related diseases such as heart disease, stroke, chronic lung disease, and cancer [1].

According to the 2006 Surgeon's General Report, The Health Consequences of Involuntary Exposure to Tobacco Smoke, exposure to secondhand smoke (SHS) adversely affects the cardiovascular system, and causes

${ }^{*}$ Corresponding author. coronary heart disease and lung cancer. Furthermore, no level of exposure is safe [2]. Evidence has shown that the concentrations of many cancer-causing and toxic chemicals are higher in SHS than in the smoke inhaled by smokers [2]. As a result, SHS causes harmful effects on the cardiovascular system, and can increase the risk for heart attack, even among nonsmokers [3].

In the 2010 Surgeon General's Report, How Tobacco Smoke Causes Disease, researchers concluded that breathing SHS causes immediate damage to the lungs due to the inhalation of a multitude of fine particles, gases, and chemicals that result in irritation and inflammation of endothelial tissue (tissue lining body cavities) [4]. People living with chronic illnesses such as asthma, emphysema, chronic bronchitis, chronic obstructive pulmonary disease, or other respiratory conditions, may experience a worsening of symptoms (e.g. wheeze, shortness of breath, cough) when exposed to SHS [5]. It has been also determined that babies of pregnant women who 
are exposed to SHS may have decreased birth weight and have a higher risk of sudden infant death syndrome $[2,6]$. Because SHS exposure affects the air quality in the immediate surroundings, vulnerable populations - such as young children who reside in homes with parents who smoke - have higher prevalence of sudden infant death syndrome, ear problems, respiratory infections, and asthma attacks than those who live in nonsmoking homes $[2,3]$.

One opportunity for providing advice about the dangers of SHS is the primary health care visit, where primary care providers (PCPs) can educate patients about the adverse outcomes of SHS exposure. Little is known about what health professionals say to patients regarding SHS exposure, so our research examines three situations: what providers say to patients with children, regarding the need to prevent exposure of the children to SHS; providers' advise to smokers, about the need to avoid exposing others to SHS in homes and cars; and providers' advise to nonsmokers about avoid SHS exposure. Using findings from a Web-based physician survey, we report on the prevalence in 2008, 2009, and 2010 of PCPs' advise to patients about SHS exposure.

\section{Method}

The physician sample of the DocStyles survey consisted of family/general practitioners, general internists, and obstetrician/gynecologists. Physicians responded to a series of identical questions on provider advice practices in each of the 3 years. DocStyles is an annual Web-based survey conducted by Epocrates Incorporated (http://www. epocrates.com/honors). Respondents were volunteers from the Epocrates Honors Panel, an opt-in panel of medical practitioners [7]. Other studies using DocStyles have reported details on the sampling methodology $[8,9]$. Each physician's first name, last name, date of birth, and medical school and graduation data were verified by comparison with the American Medical Association's (AMA's) master file at the time of panel registration. Epocrates randomly selected a sample of eligible physicians from their main database to load into their invitation database. The sample was drawn to match AMA master file proportions for age, gender, and region. Physicians were screened to include only those who practice in the United States; actively see patients; work in an individual, group, or hospital practice; and who have been practicing medicine for at least 3 years. Respondents were not required to participate and could exit the survey at any time. The estimated time for online completion of the survey varied by specialty and ranged from approximately 19 to 30 minutes. Invitations were sent out to the Web-based survey.

The DocStyles survey instrument was developed by
Porter Novelli with technical assistance provided by federal public health agencies and other non-profit and for-profit clients. The survey contained over 100 questions, some with multiple subparts. The survey was designed to provide insight into healthcare providers' attitudes and counseling behaviors on a variety of health issues. The 2008, 2009, and 2010 surveys were administered in July during each of the 3 years; the response rates were $22.0 \%, 45.8 \%$, and $45.9 \%$, respectively. Physicians were paid an honorarium of $\$ 40$ to $\$ 95$ for completing the survey.

\subsection{Survey Items}

PCP personal characteristics consisted of sex, specialty (e.g., family/general practitioner, internist, obstetrician/ gynecologist), age $(\leq 40,>40)$, and race/ethnicity (white, non-Hispanic, other). Practice characteristics such as number of patients seen per week $(\leq 100,>100)$, number of years in practice $(\leq 10,>10)$, and practice setting type (individual, group, hospital) were also collected. We examined reported data on all personal and practice characteristics provided.

\section{Secondhand Smoke Strategies}

Three questions probed PCPs about SHS exposure. First, physicians were asked, Do you advise your patients with children to keep their children from being exposed to smoke from cigarettes or other tobacco products (that is, secondhand smoke)? Respondents were asked two additional SHS questions: Do you advise your patients who do not smoke tobacco or use other tobacco products to avoid being exposed to secondhand smoke? and Do you advise your patients who smoke tobacco or use other tobacco products to create smoke-free homes and cars? Response options for all three questions were "yes" or "no".

\subsection{Statistical Analysis}

Data were analyzed using SAS version 9.2 (SAS Institute, Inc., Cary, North Carolina) and SUDAAN (Version 9.0; Research Triangle Institute, Research Triangle Park, NC) was used to account for the random sample design. We compared the respondents with non-respondents and did not find any differences in the personal and practice characteristics. Prevalence (\%) and 95\% confidence intervals (CIs) were reported for advising against SHS exposure, and were categorized by PCP personal and practice characteristics. Multivariate logistic regression models were used to calculate odds ratios (ORs) for offering patients advice regarding SHS exposure (versus lack of advice). Using 2010 data, separate logistic regression models were run to examine individual comparisons (demographics, patients per week, years in practice and practice setting) for providing advice towards SHS ex- 
posure. Statistical significance was determined at $p<0.05$.

\section{Results}

Data for each of the 3 years surveyed consisted of approximately 1250 health care providers (Table 1). The majority of the Web-based sample was male, family/general practitioners, over 40 years of age, and white nonHispanic. We examined 100 patients per week or less, were in practice over 10 years, and were in group practice settings.

\subsection{Advice to Patients Who Were Also Parents}

The prevalence of advice to patients with children to keep their children from being exposed to SHS was high and remained high over the 3 years: $94.0 \%$ in 2008 , $91.7 \%$ in 2009, and $93.6 \%$ in 2010 (Table 2). Among specific primary care specialties, the prevalence was lowest among obstetrician/gynecologists (OBs/GYNs): 86.6\% (2008), 88.4\% (2009), and 89.2\% (2010). Among other racial/ethnic PCPs, the prevalence was $95.8 \%$ (2008), 88.4\% (2009), and 91.7\% (2010). The prevalence of PCPs' advice for those in practice 10 years or more was $92.5 \%$ (2008), 92.2\% (2009), and 93.4\% in 2010 .

Table 1. Characteristics of primary care provider sampleDocStyles 2008-2010.

\begin{tabular}{|c|c|c|c|}
\hline & \multicolumn{3}{|c|}{ Sample year } \\
\hline & 2008 & 2009 & 2010 \\
\hline Characteristic & $\mathrm{N}$ & $\mathrm{N}$ & $\mathrm{N}$ \\
\hline Overall & 1250 & 1250 & 1250 \\
\hline \multicolumn{4}{|l|}{ Gender } \\
\hline Male & 959 & 877 & 839 \\
\hline Female & 291 & 373 & 411 \\
\hline \multicolumn{4}{|l|}{ Specialty } \\
\hline Family/general practitioner & 510 & 609 & 539 \\
\hline General internist & 490 & 391 & 461 \\
\hline Obstetrician/gynecologist & 250 & 250 & 250 \\
\hline \multicolumn{4}{|l|}{ Age (years) } \\
\hline$\leq 40$ & 518 & 482 & 461 \\
\hline$>40$ & 732 & 768 & 789 \\
\hline \multicolumn{4}{|l|}{ Race/ethnicity } \\
\hline White non-Hispanic & 910 & 885 & 886 \\
\hline Other $^{\mathrm{a}}$ & 290 & 318 & 364 \\
\hline \multicolumn{4}{|l|}{ Patients per week } \\
\hline$\leq 100$ & 693 & 722 & 802 \\
\hline$>100$ & 557 & 528 & 448 \\
\hline \multicolumn{4}{|l|}{ Years in practice } \\
\hline$\leq 10$ & 567 & 516 & 501 \\
\hline$>10$ & 683 & 732 & 749 \\
\hline \multicolumn{4}{|l|}{ Practice setting } \\
\hline Individual & 224 & 234 & 228 \\
\hline Group & 808 & 792 & 771 \\
\hline Hospital & 218 & 224 & 251 \\
\hline
\end{tabular}

${ }^{a}$ Other refers to Black, Hispanic, Asian, and other racial/ethnic groups.

\subsection{Advice to Smokers}

Overall, PCPs' advice to smokers to avoid SHS exposure in their homes and cars varied little over the 3 -year period: $83.5 \%$ in $2008,79.7 \%$ in 2009 , and $85.5 \%$ in 2010 (Table 3). For this same period, among OBs/GYNs, the prevalence of asking smokers to avoid SHS exposure in their home and car was $74.7 \%$ in $2008,72.8 \%$ in 2009 , and $84.3 \%$ in 2010 . Among PCPs over 40 years of age, the prevalence of asking smokers to avoid SHS exposure in their home and car was $81.5 \%$ in $2008,80.6 \%$ in 2009 , and $86.2 \%$ in 2010 . For white non-Hispanic PCPs, the prevalence of asking smokers to avoid SHS exposure in their homes and cars was $83.9 \%$ in $2008,80.2 \%$ in 2009 , and $87.6 \%$ in 2010 . For PCPs in practice for more than 10 years, the prevalence of asking smokers to avoid SHS exposure in their homes and cars was $81.5 \%$ in 2008 , $81.1 \%$ in 2009 , and $85.6 \%$ in 2010 .

\subsection{Advice to Nonsmokers}

Among the SHS questions about PCP practices, the prevalence of advising nonsmokers to avoid general exposure to SHS was lowest: $75.4 \%$ in $2008,63.8 \%$ in 2009 , and $71.9 \%$ in 2010 (Table 4). Over this same period, among internists, the prevalence of advising nonsmokers to avoid any exposure to SHS was $80.0 \%$ in $2008,64.5 \%$ in 2009 , and $72.0 \%$ in 2010 . The prevalence of PCPs' advice to nonsmokers to avoid general exposure to SHS among other race/ethnicity PCPs was 79.6\% in $2008,67.9 \%$ in 2009 , and $72.3 \%$ in 2010 . The prevalence of PCP advice practices to nonsmokers to avoid general exposure to SHS among those in practice 10 years or less was $76.2 \%$ in $2008,62.2 \%$ in 2009 , and $70.4 \%$ in 2010 . The prevalence of PCPs advice practices to nonsmokers to avoid general exposure to SHS among those in individual practice settings was $79.9 \%$ in 2008 , $68.4 \%$ in 2009 , and $70.4 \%$ in 2010 .

\subsection{Comparisons of Practices by Sex, Specialty, and Other Factors}

Logistic regression analysis of PCPs advice practices toward SHS in 2010 showed that female PCPs were more likely than male PCPs (Table 5) to provide advice to smokers to avoid SHS exposure in their homes and cars $(\mathrm{OR}=1.65 ; 95 \% \mathrm{CI}=1.15-2.37)$. Internists were less likely than family/general practitioners to advise patients with children against SHS exposure $(\mathrm{OR}=0.43 ; 95 \% \mathrm{CI}$ $=0.23-0.78)$, and to advise smokers to avoid SHS exposure in their homes and cars $(\mathrm{OR}=0.47 ; 95 \% \mathrm{CI}=$ 0.32 - 0.69). OBs/GYNs were also less likely to advise patients with children against $\mathrm{SHS}$ exposure $(\mathrm{OR}=0.27$; $95 \% \mathrm{CI}=0.14-0.50)$, to advise to smokers to avoid SHS exposure in their homes and cars $(\mathrm{OR}=0.55 ; 95 \%$ 
Table 2. Estimates of advice to patients with children to keep their children from being exposed to secondhand smoke by primary care providers-DocStyles 2008-2010.

\begin{tabular}{|c|c|c|c|c|c|c|}
\hline \multirow{3}{*}{ Characteristic } & \multicolumn{6}{|c|}{ Advice to protect children from SHS exposure } \\
\hline & \multicolumn{2}{|l|}{2008} & \multirow{2}{*}{$\begin{array}{c}2009 \\
\mathrm{~N}\end{array}$} & \multicolumn{3}{|c|}{2010} \\
\hline & $\mathrm{N}$ & $\%, 95 \% \mathrm{CI}$ & & $\%, 95 \% \mathrm{CI}$ & $\mathrm{N}$ & $\%, 95 \% \mathrm{CI}$ \\
\hline Overall & 1164 & $94.0(92.7-95.3)$ & 1146 & $91.7(90.1-93.2)$ & 1157 & $93.6(92.2-95.0)$ \\
\hline \multicolumn{7}{|l|}{ Gender } \\
\hline Male & 888 & $93.5(91.9-95.0)$ & 807 & $92.0(90.2-93.8)$ & 771 & $93.2(91.5-94.9)$ \\
\hline Female & 276 & $95.8(93.5-98.1)$ & 339 & $90.9(88.0-93.8)$ & 386 & $94.4(92.1-96.6)$ \\
\hline \multicolumn{7}{|l|}{ Specialty } \\
\hline Family/general practitioner & 498 & $97.8(96.6-99.1)$ & 589 & $69.72(95.3-98.1)$ & 518 & $96.8(95.3-98.3)$ \\
\hline Internist & 452 & $93.8(91.6-95.9)$ & 336 & $86.0(8305-89.4)$ & 417 & $92.3(89.8-94.7)$ \\
\hline Obstetrician/gynecologist & 214 & $86.6(82.4-90.9)$ & 221 & $88.4(84.4-92.4)$ & 222 & $89.2(85.3-93.0)$ \\
\hline \multicolumn{7}{|l|}{ Age (years) } \\
\hline$\leq 40$ & 486 & $95.7(93.9-97.4)$ & 444 & $92.1(89.7-94.5)$ & 422 & $93.0(90.6-95.3)$ \\
\hline$>40$ & 678 & $92.9(91.0-94.7)$ & 702 & $91.4(89.4-93.4)$ & 735 & $94.0(92.3-95.7)$ \\
\hline \multicolumn{7}{|l|}{ Race/ethnicity } \\
\hline Other $^{\mathrm{a}}$ & 274 & $95.8(93.5-98.1)$ & 286 & $89.4(86.6-93.2)$ & 331 & $91.7(88.9-94.5)$ \\
\hline \multicolumn{7}{|l|}{ Patients per week } \\
\hline$\leq 100$ & 635 & $93.0(91.0-94.9)$ & 657 & $91.0(88.9-93.1)$ & 743 & $93.8(92.1-95.5)$ \\
\hline$>100$ & 529 & $95.3(93.6-97.1)$ & 489 & $92.6(90.4-94.8)$ & 414 & $93.2(90.9-95.6)$ \\
\hline \multicolumn{7}{|l|}{ Years in practice } \\
\hline$\leq 10$ & 535 & $92.5(90.5-94.5)$ & 469 & $90.9(88.4-93.4)$ & 462 & $93.5(91.4-95.7)$ \\
\hline$>10$ & 629 & $92.5(90.5-94.5)$ & 677 & $92.2(90.3-94.2)$ & 695 & $93.4(91.9-95.4)$ \\
\hline \multicolumn{7}{|l|}{ Practice setting } \\
\hline Individual & 212 & $95.1(92.2$ - 97.9) & 216 & $92.3(88.9-95.7)$ & 208 & $92.9(89.5-96.2)$ \\
\hline Group & 751 & $93.6(92.0-95.3)$ & 737 & $93.1(91.3-94.8)$ & 719 & $94.0(92.3-95.7)$ \\
\hline Hospital & 201 & $94.4(91.3-97.5)$ & 193 & $86.2(81.6-90.7)$ & 230 & $93.1(90.0-96.3)$ \\
\hline
\end{tabular}

${ }^{\mathrm{a}}$ Other refers to Black, Hispanic, Asian, and other racial/ethnic groups.

Table 3. Estimates of advice to smokers to avoid secondhand smoke exposure in their home and car by primary care providers-DocStyles 2008-2010.

\begin{tabular}{|c|c|c|c|c|c|c|}
\hline \multirow[b]{3}{*}{ Characteristic } & \multicolumn{6}{|c|}{ Advice against home and car SHS exposure } \\
\hline & \multicolumn{2}{|r|}{2008} & \multicolumn{2}{|c|}{2009} & \multicolumn{2}{|r|}{2010} \\
\hline & $\mathrm{N}$ & $\%, 95 \% \mathrm{CI}$ & $\mathrm{N}$ & $\%, 95 \% \mathrm{CI}$ & $\mathrm{N}$ & $\%, 95 \% \mathrm{CI}$ \\
\hline Overall & 1035 & $83.5(81.4-85.5)$ & 996 & $79.7(77.4-81.9)$ & 1059 & $85.5(83.6-87.5)$ \\
\hline \multicolumn{7}{|l|}{ Gender } \\
\hline Male & 785 & $82.7(80.0-84.9)$ & 687 & $78.3(75.6-81.0)$ & 695 & $83.8(81.3-86.3)$ \\
\hline Female & 205 & $86.8(82.9-90.7)$ & 309 & $82.8(79.0-86.7)$ & 364 & $89.0(86.0-92.0)$ \\
\hline \multicolumn{7}{|l|}{ Specialty } \\
\hline Family/general practitioner & 447 & $88.5(85.7-91.3)$ & 514 & $84.4(81.5-87.3)$ & 485 & $90.5(88.0-93.0)$ \\
\hline Internist & 402 & $82.7(79.4-86.1)$ & 300 & $76.7(72.5-80.9)$ & 365 & $80.4(76.7-84.0)$ \\
\hline Obstetrician/gynecologist & 186 & $74.7(69.3-80.1)$ & 182 & $72.8(67.3-78.3)$ & 209 & $84.3(79.7-88.8)$ \\
\hline \multicolumn{7}{|l|}{ Age (years) } \\
\hline$\leq 40$ & 442 & $86.3(83.4-89.3)$ & 377 & $78.2(74.5-81.9)$ & 384 & $84.4(81.1-87.7)$ \\
\hline$>40$ & 593 & $81.5(78.6-84.3)$ & 619 & $80.6(77.8-83.4)$ & 675 & $86.2(83.8-88.6)$ \\
\hline \multicolumn{7}{|l|}{ Race/ethnicity } \\
\hline Other $^{\mathrm{a}}$ & 234 & $81.8(77.3-86.3)$ & 252 & $79.3(74.8-83.7)$ & 291 & $80.6(76.5-84.7)$ \\
\hline \multicolumn{7}{|l|}{ Patients per week } \\
\hline$\leq 100$ & 568 & $82.6(79.7-85.4)$ & 567 & $78.5(75.5-81.5)$ & 675 & $84.9(82.4-87.4)$ \\
\hline$>100$ & 467 & $84.6(81.6-87.6)$ & 429 & $81.3(77.9-84.6)$ & 384 & $86.7(83.5-89.8)$ \\
\hline \multicolumn{7}{|l|}{ Years in practice } \\
\hline$\leq 10$ & 481 & $85.9(83.0-88.8)$ & 401 & $77.7(74.1-81.3)$ & 422 & $85.4(82.3-88.5)$ \\
\hline$>10$ & 554 & $81.5(78.5-84.4)$ & 595 & $81.1(78.2-83.9)$ & 637 & $85.6(83.1-88.1)$ \\
\hline \multicolumn{7}{|l|}{ Practice setting } \\
\hline Individual & 183 & $82.4(77.4-87.4)$ & 190 & $81.2(76.2-86.2)$ & 194 & $86.6(82.1-91.1)$ \\
\hline Group & 676 & $84.2(81.7-86.7)$ & 632 & $79.8(77.0-82.6)$ & 648 & $84.7(82.2-87.3)$ \\
\hline Hospital & 176 & $81.9(76.7-87.0)$ & 174 & $77.7(72.2-83.1)$ & 217 & $87.2(83.0-91.3)$ \\
\hline
\end{tabular}

${ }^{\mathrm{a}}$ Other refers to Black, Hispanic, Asian, and other racial/ethnic groups. 
Table 4. Estimates of advice to nonsmokers to avoid general exposure of secondhand smoke by primary care providersDocStyles 2008-2010.

\begin{tabular}{|c|c|c|c|c|c|c|}
\hline \multirow[b]{3}{*}{ Characteristic } & \multicolumn{6}{|c|}{ Advice to nonsmokers to avoid SHS exposure } \\
\hline & \multicolumn{2}{|r|}{2008} & \multicolumn{2}{|c|}{2009} & \multicolumn{2}{|r|}{2010} \\
\hline & $\mathrm{N}$ & $\%, 95 \% \mathrm{CI}$ & $\mathrm{N}$ & $\%, 95 \% \mathrm{CI}$ & $\mathrm{N}$ & $\%, 95 \% \mathrm{CI}$ \\
\hline Overall & 934 & $75.4(73.0-77.8)$ & 798 & $63.8(61.2-66.5)$ & 889 & $71.9 \%,(69.4-74.4)$ \\
\hline \multicolumn{7}{|l|}{ Gender } \\
\hline Male & 707 & $74.3(71.5-77.0)$ & 557 & $63.5(60.3-66.7)$ & 589 & $71.0(67.9-74.1)$ \\
\hline Female & 227 & $79.4(74.7-84.1)$ & 241 & $64.6(59.8-69.5)$ & 300 & $73.7(69.4-78.0)$ \\
\hline \multicolumn{7}{|l|}{ Specialty } \\
\hline Family/general practitioner & 390 & $77.3(73.6-80.9)$ & 403 & $66.2(62.4-67.0)$ & 411 & $76.8(73.2-80.4)$ \\
\hline Internist & 387 & $80.0(76.3-83.5)$ & 255 & $64.5(59.7-69.2)$ & 326 & $72.0(67.8-76.1)$ \\
\hline Obstetrician/gynecologist & 157 & $63.1(57.1-69.0)$ & 143 & $57.2(51.1063 .3)$ & 152 & $61.0(55.0-67.1)$ \\
\hline \multicolumn{7}{|l|}{ Age (years) } \\
\hline$\leq 40$ & 392 & $76.9(73.2-80.5)$ & 300 & $62.2(57.9-66.6)$ & 326 & $71.5(67.3-75.6)$ \\
\hline$>40$ & 542 & $74.5(71.3-77.6)$ & 498 & $64.8(61.5-68.2)$ & 563 & $72.1(68.9-75.2)$ \\
\hline \multicolumn{7}{|l|}{ Race/ethnicity } \\
\hline White non-Hispanic & 658 & $73.2(70.3-76.1)$ & 547 & $61.8(58.6-65.0)$ & 628 & $71.7(68.7-74.7)$ \\
\hline Other $^{\mathrm{a}}$ & 230 & $79.6(74.9-84.2)$ & 216 & $67.9(62.8-73.1)$ & 261 & $72.3(67.7-76.9)$ \\
\hline \multicolumn{7}{|l|}{ Patients per week } \\
\hline$\leq 100$ & 501 & $73.1(69.8-76.5)$ & 434 & $60.1(56.5-63.7)$ & 562 & $71.0(67.8-74.1)$ \\
\hline$>100$ & 433 & $78.3(74.9-81.7)$ & 364 & $68.9(65.0-72.9)$ & 327 & $73.5(69.4-77.6)$ \\
\hline \multicolumn{7}{|l|}{ Years in practice } \\
\hline$\leq 10$ & 426 & $76.2(72.8-79.7)$ & 321 & $62.2(58.0-66.4)$ & 347 & $70.4(66.4-74.4)$ \\
\hline$>10$ & 508 & $74.8(71.5-78.1)$ & 477 & $65.0(61.5-68.4)$ & 542 & $72.9(69.7-76.0)$ \\
\hline \multicolumn{7}{|l|}{ Practice setting } \\
\hline Individual & 179 & $79.9(74.7-85.2)$ & 160 & $68.4(62.4-74.3)$ & 159 & $70.4(64.4-76.3)$ \\
\hline Group & 587 & $73.5(70.4-76.5)$ & 504 & $63.6(60.3-67.0)$ & 548 & $71.6(68.4-74.2)$ \\
\hline Hospital & 168 & $78.1(72.6-83.7)$ & 134 & $59.8(53.4-66.2)$ & 182 & $74.0(68.5-79.5)$ \\
\hline
\end{tabular}

${ }^{\mathrm{a}}$ Other refers to Black, Hispanic, Asian, and other racial/ethnic groups.

Table 5. Logistic regression of primary care providers' advice towards exposure of secondhand smoke—DocStyles, 2010.

\begin{tabular}{|c|c|c|c|}
\hline & \multicolumn{3}{|c|}{ Effect of advice } \\
\hline & Protect children from SHS exposure & Against home and car SHS exposure & Nonsmokers to avoid SHS exposure \\
\hline Characteristic & OR $(95 \% \mathrm{CI})$ & OR $(95 \% \mathrm{CI})$ & OR $(95 \% \mathrm{CI})$ \\
\hline \multicolumn{4}{|l|}{ Gender } \\
\hline Male & Reference & Reference & Reference \\
\hline Female & $1.28(0.77-2.13)$ & $1.68\left(1.16-2.43^{*}\right.$ & $1.21(0.92-1.60)$ \\
\hline \multicolumn{4}{|l|}{ Specialty } \\
\hline Family/general practitioner & Reference & Reference & Reference \\
\hline Internist & $0.43(0.24-0.80)^{*}$ & $0.46(0.31-0.69)^{*}$ & $0.79(0.58-1.07)$ \\
\hline Obstetrician/gynecologist & $0.25(0.14-0.47)^{*}$ & $0.56(0.35-0.90)^{*}$ & $0.45(0.32-0.62)^{*}$ \\
\hline \multicolumn{4}{|l|}{ Age (years) } \\
\hline$\leq 40$ & Reference & Reference & Reference \\
\hline$>40$ & $1.17(0.59-2.33)$ & $1.16(0.72-1.88)$ & $0.86(0.59-1.25)$ \\
\hline \multicolumn{4}{|l|}{ Race/ethnicity } \\
\hline White non-Hispanic & Reference & Reference & Reference \\
\hline Other $^{\mathrm{a}}$ & $0.66(0.41-1.07)$ & $0.58(0.41-0.81)^{*}$ & $1.03(0.78-1.37)$ \\
\hline \multicolumn{4}{|l|}{ Patients per week } \\
\hline$\leq 100$ & Reference & Reference & Reference \\
\hline$>100$ & $0.86(0.54-1.38)$ & $1.20(0.84-1.71)$ & $1.15(0.88-1.51)$ \\
\hline \multicolumn{4}{|l|}{ Years in practice } \\
\hline$\leq 10$ & Reference & Reference & Reference \\
\hline$>10$ & $0.98(0.49-1.96)$ & $0.98(0.60-1.60)$ & $1.39(0.97-1.99)$ \\
\hline \multicolumn{4}{|l|}{ Practice setting } \\
\hline Individual & Reference & Reference & Reference \\
\hline Group & $1.32(0.71-2.47)$ & $0.91(0.59-1.43)$ & $1.12(0.80-1.57)$ \\
\hline Hospital & $1.32(0.60-2.91)$ & $1.48(0.83-2.65)$ & $1.19(0.76-1.86)$ \\
\hline
\end{tabular}

CI: confidence interval; OR: odds ratio. OR adjusted for sex, age, race/ethnicity. ${ }^{\text {a } O t h e r ~ r e f e r s ~ t o ~ B l a c k, ~ H i s p a n i c, ~ A s i a n, ~ a n d ~ o t h e r ~ r a c i a l / e t h n i c ~ g r o u p s . ~}$ *Significant difference, $p<0.05$. 
$\mathrm{CI}=0.35-0.87)$, and to provide advice to nonsmokers to avoid general exposure to SHS (OR $=0.47 ; 95 \% \mathrm{CI}=$ 0.34 - 0.65) compared with family/general practitioners. Other race/ethnicity PCPs were also less likely than whites to provide advice to smokers to avoid SHS exposure in their homes and cars $(\mathrm{OR}=0.58 ; 95 \% \mathrm{CI}=0.41$ 0.81 ). Logistic regression analyses were performed in 2008 and 2009 and similar patterns were found (data not shown).

\section{Discussion}

These Web-based data show that nearly all physicians reported that they discuss SHS risks with their patients. Overwhelmingly, as many as $90 \%$ of PCP advised patients with children to keep their children from being exposed to SHS, $80 \%$ advised patients who smoke to avoid exposing others to SHS in their homes and cars, and $70 \%$ advised nonsmokers to avoid general exposure to SHS. Although there are few other national studies on this topic, Burnett and Young found that $96 \%$ of providers reported that they sometimes/often screen for any SHS exposure [10]. Physicians are looking for opportunities to more consistently address, in their clinical practices, the health risks of SHS [11]. Since patients are open to SHS counseling and adults who are counseled on SHS exposure report higher rates of satisfaction with their care, PCPs should screen for tobacco use and address SHS risks.

Since the mid-2000s, there has been an increased awareness of the effects of SHS [2], which likely has contributed to recommendations to clinicians to address this issue with their patients. Historically, the first government report to conclude that SHS caused disease was the 1986 Surgeon's General Report [12]; this was updated in 2006 with a second Surgeon General's Report dedicated to the adverse health effects of SHS [2]. Additionally, primary care medical societies have called on their physician members to address the dangers of SHS with their patients. For example, in a 2009 policy statement the American Academy of Pediatrics recommended documentation of SHS exposure at all clinical encounters [13]; the American College of Obstetricians and Gynecologists 2010 committee opinion recommended that pregnant women avoid SHS exposure [14], and the 2009 position paper by the American Academy of Family Practice recommended that their physicians counsel patients to avoid establishments that permit smoking and to request that family members not smoke in their homes or vehicles [15]. Finally, the Public Health Service Update in 2008, Treating Tobacco Use and Dependence, recommended that clinicians screen for tobacco use and address SHS risks with their primary care patients [16].

While helpful, these recommendations vary across the physician specialty groups by the specific clinical actions proposed and the degree to which procedures are emphasized for specialty members. It is also possible that training of family/general practitioners concentrates more on preventive medicine, which may explain why these specialties advise patients against tobacco more often than internists or obstetrician/gynecologists. Family/general practitioners regularly encounter a high volume of patients and frequently deliver primary care to children, which may account for higher prevalence of advice against home and car exposures and general exposure among nonsmokers. Further, clarity and harmonization are needed among various recommendations for SHS exposure as it relates to tobacco control efforts. Findings from a review on the treatment of smokers in the health care setting [17] suggests that it would be advantageous to society if physicians would incorporate advice towards reducing SHS exposure into their counseling strategy.

Several limitations apply to this study. First, because data were obtained from convenience samples of selfselected healthcare providers who responded to the e-mail invitation to be part of the Epocrates Honor Panel; thus, our findings are not necessarily generalizeable beyond responders in terms of being nationally representative. Second, self-reported data may introduce social desirability bias of prevention practices among physicians. Self-reported data have also been found to overestimate observational study findings $[18,19]$. Third, we cannot make inferences about physicians' routine practices in advising about exposure to SHS, as these data do not ask about frequency of counseling, amount of tobacco products, or number of years patients were using tobacco. Also, since the questions relied on recall, they may not accurately capture providers' actual behavior. Fourth, the response rates reported in this web-based survey are comparable to other studies that have used mail-in surveys $[20,21]$, but there still may be a nonresponse bias due to relatively low response rates. However, this is the first analysis that we are aware of that examines the prevalence of PCPs practices in advising on SHS exposure over time in recent years. The strength of our study is the large number of PCPs participating each year; this facilitated generation of estimates by demographic and practice characteristics on the reporting of providing SHS advice.

\section{Conclusions}

Findings suggest that a high proportion of primary care physicians address their patients SHS exposure risk. In this sample, we found that PCP advice practices included: advising patients with children to keep their children from being exposed to SHS $(94.0 \%$ in $2008,91.7 \%$ in 2009 and $93.4 \%$ in 2010); advising patients who smoke 
to avoid exposing others to SHS in their homes and cars (83.5\% in 2008, $79.7 \%$ in 2009 and $85.5 \%$ in 2010); and advising nonsmokers to avoid general exposure to SHS (75.4\% in 2008, 63.8\% in 2009 and $71.9 \%$ in 2010).

Based on our finding that $\mathrm{OBs} / \mathrm{GYNs}$ are less likely to engage in SHS counseling than other health care providers, promotion of the American College of Obstetricians and Gynecologists recommendations [14], in addition to further investigative solutions for ways to improve counseling rates, are needed. Because of the health consequences of SHS exposure, PCPs should be encouraged to address SHS exposure consistently with their patients.

\section{Acknowledgements}

The authors thank Deanne Weber for providing technical assistance with the data.

\section{Conflict of Interest Statement}

Drs. Kruger and Teplinskaya have no relevant conflict of interest to report. Dr. Fiore reports that, over the last year, he participated in a research study on smoking cessation that was funded in part by NABI Pharmaceuticals. The findings and conclusions in this report are those of the authors and do not necessarily represent the official position of the Centers for Disease Control and Prevention.

\section{REFERENCES}

[1] DHHS, "A Report of the Surgeon General: How Tobacco Smoke Causes Disease: What It Means to You," CDC, National Center for Chronic Disease Prevention and Health Promotion, Office on Smoking and Health, Atlanta, 2010.

http://www.cdc.gov/tobacco/data_statistics/sgr/2010/inde x.htm

[2] DHHS, "The Health Consequences of Involuntary Exposure to Tobacco Smoke: A Report of the Surgeon General," CDC, National Center for Chronic Disease Prevention and Health Promotion, Office on Smoking and Health, Atlanta, 2006.

http://www.cdc.gov/tobacco/data_statistics/sgr/2006/inde x.htm

[3] Institute of Medicine, "Secondhand Smoke Exposure and Cardiovascular Effects: Making Sense of the Evidence," National Academy of Sciences, Institute of Medicine, Washington, 2010. http://www.nap.edu/catalog.php?record_id=12649

[4] DHHS, "How Tobacco Smoke Causes Disease: The Biology and Behavioral Basis for Smoking-Attributable Disease: A Report of the Surgeon General," CDC, National Center for Chronic Disease Prevention and Health Promotion, Office on Smoking and Health, Atlanta, 2010. http://www.cdc.gov/tobacco/data_statistics/sgr/index.htm

[5] R. E. Schane and S. A. Glantz, "Education on the Dangers of Passive Smoking: A Cessation Strategy Past
Due," Circulation, Vol. 18, No. 15, 2008, pp. 1521-1523. doi:10.1161/CIRCULATIONAHA.108.805259

[6] Agency for Healthcare Research and Quality, "The Guide to Clinical Preventive Services 2010-2011: Recommendations of the US Preventive Services Task Force," Agency for Healthcare Research and Quality, 2011, pp. 148-149.

http://www.ahrq.gov/clinic/pocketgd1011/pocketgd1011. pdf

[7] P. Novelli, "DocStyles 2010: Methods," Porter Novelli, Washington, 2010.

[8] H. R. Wethington, B. Sherry and B. Polhamus, "Physician Practices Related to Use of BMI-for-Age and Counseling for Childhood Obesity Prevention: A Cross-Sectional Study," BMC Family Practice, Vol. 12, No. 80, 2011, pp. 1-9.

[9] K. I. Day, D. B. Friedman, J. N. Laditka, L. A. Anderson, R. Hunter, S. B. Laditka, B. Wu, L. C. McGuire and M. C. Coy, "Prevention of Cognitive Impairment: Physician Perceptions and Practices," Journal of Applied Gerontology, 2011, pp. 1-12.

[10] K. F. Burnett and P. C. Young, "Ask, Advise, Assist: Pediatric and Passive Smoke Exposure," Clinical Pediatrics, Vol. 38, No. 6, 1999, pp. 339-345. doi:10.1177/000992289903800604

[11] G. C. Williams, S. A. Williams and R. J. Korn, "Secondhand Smoke (SHS) Deserves More than Secondhand Attention: Modifying the 5As Model to Include Counseling to Eliminate Exposure," Families Systems \& Health, Vol. 2, No. 3, 2005, pp. 266-277. doi:10.1037/1091-7527.23.3.266

[12] USDHHS, "The Health Consequences of Using Smokeless Tobacco: A Report of the Advisory Committee to the Surgeon General," US Department of Health and Human Services, Public Health Service, Bethesda, 1986. http://profiles.nlm.nih.gov/ps/access/NNBBFC.pdf

[13] American Academy of Pediatrics, "Policy StatementTobacco Use: A Pediatric Disease," Pediatrics, Vol. 124, No. 5, 2009, pp. 1474-1475. doi:10.1542/peds.2009-2114

[14] American College of Obstetricians and Gynecologists, "Committee Opinion, No. 471," Obstetrics \& Gynecology, Vol. 116, No. 5, 2010, pp. 1241-1244.

[15] American Academy of Family Physicians, "Tobacco Use and Prevention-Position Paper," American Academy of Family Physicians, 2012.

http://www.aafp.org/online/en/home/policy/policies/t/tob accoprevcess.html

[16] M. C. Fiore, C. R. Jaen, T. B. Baker, et al., "Treating Tobacco Use and Dependence: 2008 Update: Clinical Practice Guidelines," US Department of Health and Human Service, Rockville, 2008, p. 69.

http://www.surgeongeneral.gov/tobacco/treating_tobacco _use08.pdf

[17] M. C. Fiore and T. B. Baker, "Treating Smokers in the Health Care Setting," New England Journal of Medicine, Vol. 365, No. 13, 2011, pp. 1222-1231. doi:10.1056/NEJMcp1101512

[18] M. B. Conroy, N. E. Majchrzak, C. B. Silverman, Y 
Chang, S. Regan, L. I. Schneider and N. A. Rigotti, "Measuring Provider Adherence to Tobacco Treatment Guidelines: A Comparison of Electronic Medical Record Review, Patient Survey, and Provider Survey," Nicotine \& Tobacco Research, Vol. 7, Suppl. 1, 2005, pp. S35S43. doi:10.1080/14622200500078089

[19] W. E. Pollard, "Use of a Consumer Panel Survey for Public Health Communication Planning: An Evaluation of Survey Results," Proceedings of the American Statistical Association, Section on Health Policy Statistics, New York, 2002, pp. 2120-2124.

[20] D. Weber, L. S. Wolff, T. Orleans, R. E. Mockenhaupt, H.
A. Massett and K. K. Vose, "Smokers' Attitudes and Behaviors Related to Consumer Demand for Cessation Counseling in the Medical Care Setting," Nicotine \& Tobacco Research, Vol. 9, Suppl. 4, 2007, pp. 571-580. doi:10.1080/14622200701189024

[21] L. S. Wolff, H. A. Massett, E. W. Maibach, D. Weber, R. E. Mockenhaupt and S. Hassmiller, "Validating a Health Consumer Segmentation Model: Behavioral and Attitudinal Differences in Disease Prevention-Related Practices," Journal of Health Communication, Vol. 15, No. 2, 2010, pp. 167-188. doi:10.1080/10810730903528041 